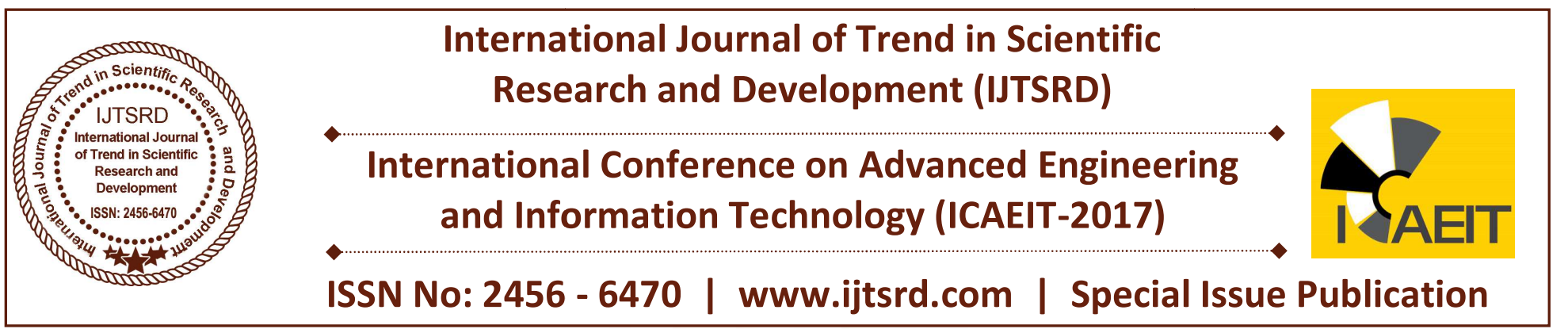

\title{
A Review on Fuzzy Sets Uncertainty Modeling In Expert Systems
}

\author{
Kayalvizhi Subramanian $^{1}$, Gunasekar Thangarasu ${ }^{2}$, Prof. Dr. Ramani Bai ${ }^{1}$ \\ ${ }^{1}$ Faculty of Built Environment, Linton University College, Negeri Sembilan, Malaysia \\ ${ }^{2}$ Department of Computer and Information Sciences, Universiti Teknologi PETRONAS, Perak, Malaysia
}

\begin{abstract}
Expert systems are well known area of artificial intelligence and have a huge impact in various fields of life. It has been widely used in managing uncertainty and vague information, which models the ability of humans to make rational decisions. One of the challenges that expert system faced is to deal with uncertainty. Even though there are many uncertainties management approaches which can deal with problems of different types. This paper reviews the trends and general information regarding the expert systems in order to highlight, classify the different approaches in terms of the applications and target area of problem solving. The concepts and techniques used in the development of selected expert systems have discussed which are medical, agriculture, and education. These can serve as a guide in selecting suitable expert systems in their area of problem solving. It is concluded that while expert systems have great potential, they remain un-established as a useful technology due to a lack of research and documentation.
\end{abstract}

Keywords: Artificial intelligence, Expert systems, Uncertainty, Fuzzy logic

\section{INTRODUCTION}

Fuzzy logic is very popular among researchers which deal with imprecise or vague information. Expert systems which adopts fuzzy logic in resolving uncertainty is known as a fuzzy expert system. Fuzzy expert system is getting popular and more research is moving towards this area. Fuzzy logic is very essential in most domains, as a fuzzy expert system had been proven quite successful in many areas which deal with vague knowledge [1]. Actually, the general purpose reasoning (GPS) techniques, developed before expert system, which separates the problem solving from knowledge are now considered to be too limited in solving real time problems. This is due to the fact that the encoding rich source of knowledge within a problem is the most important [2]. Besides, expert system which is developed to be well-focused on a narrow issue is more efficient and effective than a system which is able to address broad areas of problem. In solving a problem, human expert often faces problematic information. This could be due to the unreliable information source or lack of adequate information to make a decision in solving a problem [3]. However, human experts can still make judgments by adapting to the situation and provide a probable solution intelligently or with their past experiences. Nevertheless, the ability of human expert to deal with problematic information is difficult to be replicated into an expert system. Researchers are constantly finding ways to manage inexact information in expert system which are close to the human expert's ability [4].

\section{Fuzzy Sets}

Most of our traditional tools for formal modeling, reasoning and computing are crisp, deterministic and precise in character. Fuzziness can be found in many areas of daily life, such as engineering, medicine, meteorology, manufacturing, and others. According to Zadeh [5], the notation of a fuzzy set provides a convenient point of departure for the construction of a conceptual framework which parallel in many respects the framework used in the case of ordinary sets, but is more general than the latter and, potentially, may prove to have a much wider scope of applicability, particularly in the fields of pattern classification and information processing. Essentially, 
such a framework provides a natural way of dealing with problems in which thesource of imprecision is the absence of sharply defined criteria of class membership rather than the presence of random variables. Fuzziness has so far not been defined uniquely semantically, and probably never will be. It will mean different things, depending on the application area and the way it is measured.

Definition: A fuzzy set is built from a reference set called the universe of discourse. The reference set is never fuzzy. Assume that is the universe of discourse, then a fuzzy set $A$ in is defined as a set of ordered pairs.

\section{( )}

Where the membership is function of $\mathrm{A}$ and is the degree of membership of $x$ in A.

Definition: The cardinality and the relative cardinality of a fuzzy set A, defined over a finite universe $\mathrm{U}$, are defined as

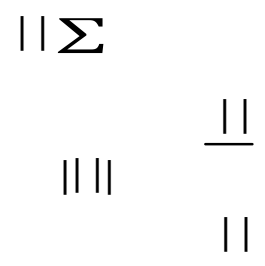

\section{Modeling of Uncertainty}

Real situations are very often uncertain or vague in a number of ways. Due to lack of information, the future state of the system might not be known completely. This type of uncertainty has long been handled appropriately by probability theory and statistics. Uncertainty has been a very important topic for several centuries. There are numerous methods and theories which claim to be the only proper tool to model uncertainties. In general, however, they do not even define sufficiently or only in a very specific and limited sense what is meant by uncertainty. If considered uncertainty as a subjective phenomenon, can and ought to be modeled by very different theories, depending on the causes of uncertainty, the type and quantity of available information, the requirement of the observer etc. In this sense, fuzzy set theory is certainly also one of the theories which can be used to model specific types of uncertainly under specific types of circumstances. It might then compete with other theories, but it might also be the most appropriate way to model this phenomenon for well-specified situations [6].
In dual logic, truth values can be „true (1) or „false" $(0)$ and operators are defined via truth tables. A and B represent two sentences or statements which can be true (1) or false (0). These statements can be combined by operators. The truth values of the combined statements are shown in table-1 the columns under the respective operators „and", "inclusive or", „exclusive or", implication, and so on. Hence, the truth values in the columns define the respective operators. Considering the modus ponens as one tautology:

Here four assumptions are being made:

1. A and B are crisp.

2. A in premise is identical to A in implication.

3. True $=$ absolutely true

False $=$ absolutely false.

4. There exist only two quantifiers: "All” and

"There exists at least one case".

Table 1: Truth table of Dual logic

\begin{tabular}{|c|c|c|c|c|c|c|c|}
\hline $\mathbf{A}$ & $\mathbf{B}$ & $\wedge$ & $\vee$ & $\mathbf{X} \vee$ & & $\leftrightarrow$ & $?$ \\
\hline 1 & 1 & 1 & 1 & 0 & 1 & 1 & 1 \\
\hline 1 & 0 & 0 & 1 & 1 & 0 & 0 & 1 \\
\hline 0 & 1 & 0 & 1 & 1 & 1 & 0 & 0 \\
\hline 0 & 0 & 0 & 0 & 0 & 1 & 1 & 0 \\
\hline
\end{tabular}

\section{Fuzzy Expert Systems}

An expert systems technology is to provide a mechanism for building the institutional or corporate memory of the firm. That is expert system are being used to preserve or document knowledge so that one's knowledge and experiential learning would not be lost once that individual retires or leaves the firm [7]. An expert system uses human knowledge captured in a computer to solve problems that ordinarily require human expertise. The expert system may also be defined as an intelligent computer program that uses knowledge and inference procedures to solve problems that was difficult enough to acquire significant human expertise for their solutions. During the last three decades, the potential of electronic data processing has been used to an increasing degree of support human decision making in different ways. In the 1960s, the management information system (MIS) created probably exaggerated hopes for managers. Since the late 1970s and early 1980s, decision support system (DSS) found their way into management and engineering. The knowledge-based expert systems have been applied, since the mid-1980s to solve management problems [6]. It is generally assumed 
that expert systems will increasingly influence decision-making processes in business in the future.

It can be expected that in the future these decision support systems will contain to an increasing degree features including evaluation, diagnosis, and prediction. In attempting to match the performance of human experts, the key to solve the problem often lies more in specific knowledge of how to use the relevant facts than in generating a solution from some general logical principles. Human experts achieve outstanding performance because they are knowledgeable [8]. Conventional software engineering is based on procedural programming languages. The tasks to be programmed have to be well understood, the global flow of the procedure has to be determined, and the algorithmic details of each subtask have to be known before actual programming may proceed. Debugging often represents a huge investment of time, and there is little hope of automatically explaining how the results are derived. Later modification or improvement of a program becomes very difficult.

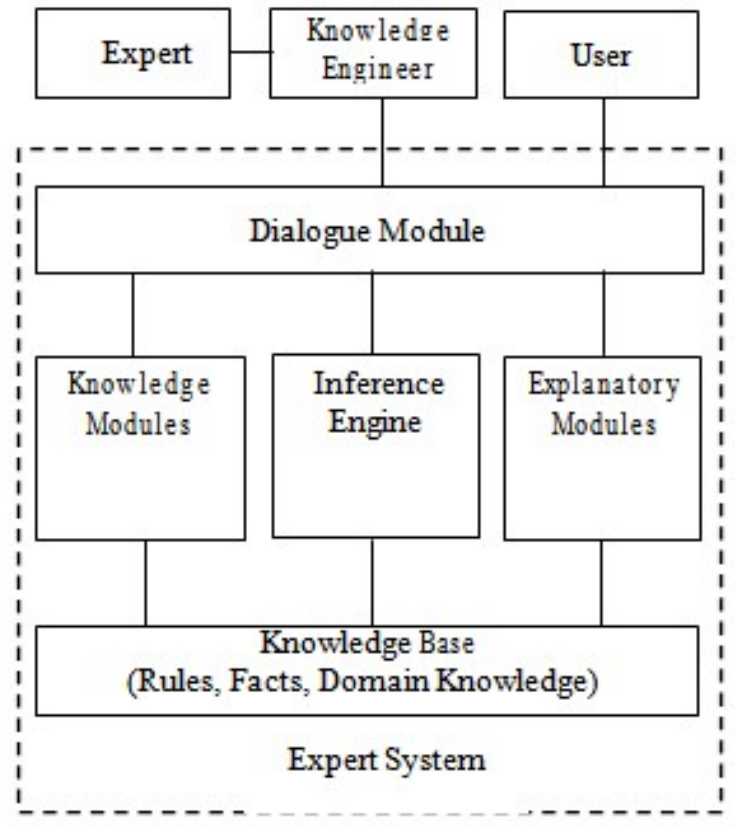

Figure 1: Expert System

An expert system is defined as "a computer program designed to model the problem solving ability of human expert" [10]. It is also defined as "a system that uses human knowledge captured in a computer to solve problems that ordinarily require human expertise". An intelligent computer program that uses knowledge and inference procedures to solve problems that was difficult enough to acquire significant human expertise for their solution.

Table 2: Top five ranking countries' research on AI topics (ScImago Lab, 2016)

\begin{tabular}{|l|l|l|}
\hline Rank & \multicolumn{1}{|c|}{ Country } & \multicolumn{1}{|c|}{$\begin{array}{c}\text { Numbe of } \\
\text { Documents }\end{array}$} \\
\hline & Year (1996-2016) & Numbers \\
\hline 1 & United Sates & $1,01,93,964$ \\
\hline 2 & China & $45,95,249$ \\
\hline 3 & United Kingdom & $28,98,927$ \\
\hline 4 & Germany & $25,70,206$ \\
\hline 5 & Japan & $23,67,977$ \\
\hline 9 & India & $13,02,605$ \\
\hline \multicolumn{3}{|c|}{ Total Counties : 239 } \\
\hline \multicolumn{3}{|c|}{ Total Documents: 44702535 } \\
\hline \multicolumn{2}{|c|}{} \\
\hline
\end{tabular}

The statistic data for the subject research of AI from year 1996s until 2016s as can refer in Table-2 has shown that there are positively increment number of researches. Figure-2 has shown the graphical representation of AI research. These data proves that more researchers or academicians from worldwide countries have highly concerned and actively involved in the studying areas of the AI. The Indian academicians and researcher collaboration with the industrial sectors for the current last 10 years indicates the improved of ranking and percentage of number of researches

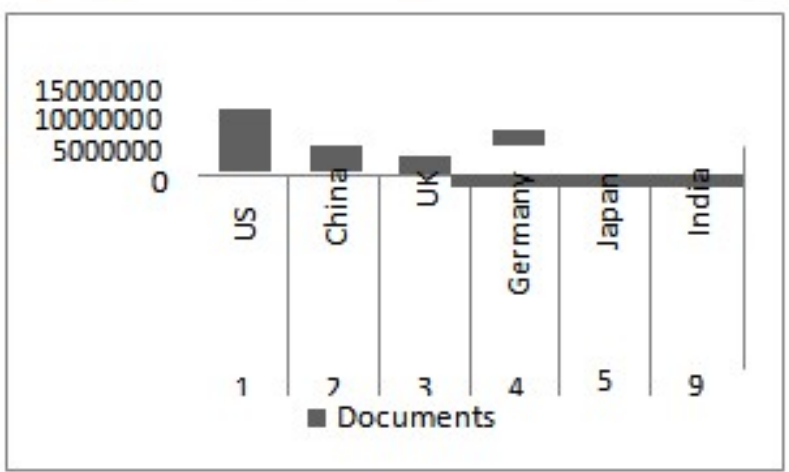

Figure 2: The total research of the AI from 1996-2016 (ScImago Lab, 2016)

An expert system is a computer program that solves problems that heretofore required significant human expertise by using explicitly represented domain knowledge and computational decision procedures [8]. The attributes of expert system include:

It has separate domain-specific knowledge and problem-solving methodology Should think the way the human expert does.

Its dynamic knowledge base should be expandable and modifiable. 
Minimize the time needed to transfer the expert's knowledge to the knowledge base.

Should interact with the language natural to the domain expert.

The control strategy should be simple and usertransparent.

Should be an inexpensive framework for building Should be able to reason under conditions of uncertainty and insufficient information.

Should be able to explain why a fact is needed to complete the line of reasoning.

Should be capable of learning from experience.

\section{Benefits of Expert Systems}

Expert system offers an environment where the good capabilities of humans and the power of computers can be incorporated to overcome many of the limitations. Expert system have many benefits [9] which are (a) increase the probability, frequency and consistency of making good decisions, (b) help distribute human expertise, (c) facilitate real time, low cost expert level decisions by the no expert, (e) enhance the utilization of most of the available data, (f) permit objectively by weighing evidence without bias and without regard for the user's personal and emotional reactions ( $g$ ) free up the mind and time of the human expert to enable the person to concentrate on more creative activities, (h) encourage investigations into the subtle areas of a problem, (i) expert system gives emphasis on individual student by keeping record of their learning ability and speed and (j) expert system provides a convenient environment to ask queries and find out their solutions.

\section{Applications of Expert Systems}

The fuzzy set theory has been successfully applied in various domains. The most important application areas are the fuzzy control, the fuzzy diagnosis, the fuzzy data analysis and fuzzy classifications [10]. The applications are

Its applications spread in a wide range i.e., in industrial and commercial problem etc.
Diagnosis and troubleshooting of devices and system of all kinds

Planning and scheduling

Configuration of manufactured objects

Financial decision making

Knowledge publishing

Process monitoring and control

Nowadays a large number of real-world applications take advantage of the approximate reasoning. Many other applications have been used like neural networks, the genetic algorithms, the evolutionary programming, the chaos theory, etc.

\subsection{Medical Expert Systems}

Technologies in medical treatment are important as well as during pre-treatment of medical consultation, diagnosis disease until the actual treatment by a specialist or doctor. Not many medical practitioners who have enough expertise and experience to consult patients about diagnosis and treatment a certain highrisk diseases, especially in most developing countries like south of Asian, African and third world countries. Furthermore, patients need to wait in longer period before diseases have been diagnosed by a specialist and when the treatment is stated, it may already late and the patient could be suffered for the whole life or in certain case mortality of patients cannot be avoided [11].

Another alternative approach in uncertainty management is the certainty-factor model, which is used in MYCIN [12]. MYCIN is an expert system used to assist medical practitioners in diagnosing blood infections and diseases. The certainty-factor is developed to address the limitation of the probabilistic approach as described previously. The certaintyfactor value is used to determine the certainty of the system regarding the hypothesis made. In order to build the certainty-factor systems, the certainty-factor values must be acquired from medical experts. These values are indeed based on the medical expert subjective interpretation without considering any of the probability rules [13]. 
International Journal of Trend in Scientific Research and Development (IJTSRD) | ISSN: 2456-647

Table 3: List of Medical Expert systems

\begin{tabular}{|c|l|}
\hline \multicolumn{2}{|c|}{ Medical Field } \\
\hline E. Systems & \multicolumn{1}{c|}{ Descriptions } \\
\hline PXDES & $\begin{array}{l}\text { Lung disease, X-ray diagnosis } \\
\text { Takes lungs picture from the upper side of body which looks like a shadow. } \\
\text { The shadow is used to determine the type and degree of hardness. }\end{array}$ \\
\hline CaDet & $\begin{array}{l}\text { It is for early cancer detection. } \\
\text { Clinical data related to early cancer detection and cancer risk factors were collected and } \\
\text { incorporated in the database. }\end{array}$ \\
\hline DXplain & $\begin{array}{l}\text { It is used for diagnosis } \\
\text { Its data based contain approximately 4500 suggestion over 2000 different diseases. }\end{array}$ \\
\hline MYCIN & $\begin{array}{l}\text { It performs a task normally done by a human expert. } \\
\text { It attempts to recommend appropriate therapies for patient } \\
\text { with bacterial infections } \\
\text { It uses LISP structures for writing internal rules. } \\
\text { It uses these rules to reason backward to the clinical data available from its goal of finding } \\
\text { disease-causing organism. }\end{array}$ \\
\hline
\end{tabular}

\subsection{Agriculture Expert Systems}

Nowadays, the expert system is widely used in agriculture exclusively for diagnosing and managing pests. These pest problems are mainly dependent upon human experts in their diagnosis and getting recovery. The involved human experts are very scarce, inconsistent in their day-to-day decisions, unable to comprehend large amounts of data quickly, unable to retain large amounts of data in memory, subject to deliberate or inadvertent bias in their actions and can deliberately avoid decision responsibilities. The farmers often rely on agricultural specialists and advisors to provide information for decision making

to get rid of problems related to pests and diseases [14].

Different domains of agriculture are highlighted where expert systems can play an important role for an expert in transferring expert-driven knowledge instantly at the level of a farmer's field. The role of expert system in agriculture along with details of expert system developed in the different field of agriculture and also possibilities of designing, developing and implementation of an expert system for agriculture has shown in the table- 4 .

Table 4: List of agriculture Expert systems

\begin{tabular}{|c|l|}
\hline \multicolumn{2}{|c|}{ Agriculture Field } \\
\hline E. Systems & \multicolumn{1}{c|}{ Descriptions } \\
\hline $\begin{array}{c}\text { CROP- } \\
\text { DOCTOR }\end{array}$ & $\begin{array}{l}\text { Developed by National Institute of Agricultural Extension Management Its main } \\
\text { work is to diagnose pests and disease for rice crop and suggest preventive measures It } \\
\text { has knowledge about diseases and pests for identification and suggesting preventive. }\end{array}$ \\
\hline AGREX & $\begin{array}{l}\text { It gives the correct advice to farmers. } \\
\text { Topics of advice are fertilizer application, crop protection, Irrigation scheduling, and } \\
\text { diagnosis of disease in paddy and post-harvest technology of fruit and vegetables. }\end{array}$ \\
\hline Wheat Crop & $\begin{array}{l}\text { Developed by Pakistan Agricultural Research Council. } \\
\text { Problem covered in diseases and pests normally encountered in wheat. }\end{array}$ \\
\hline $\begin{array}{c}\text { Rapeseed- } \\
\text { Mustard }\end{array}$ & $\begin{array}{l}\text { Alternaria blight, white rust and white rot, downy mildew complex, powdery } \\
\text { mildew, while rot of rapeseed mustard. }\end{array}$ \\
\hline
\end{tabular}

\subsection{Education and Training Expert Systems}

Current education, the learning process and training aid tools among students are well developed by advanced technology. The traditional classroom teaching method may be most popular teaching methodology these days and may remain on top for quite some years. The traditional chalk and talk method have several shortcomings, including limited time spent on various topics, limited access to teachers and difficulty in transferring lecture information to the real world situations. Because of all these drawbacks innovative and interactive learning methodologies are gaining importance and so is the use of expert systems in the field of education. In the modern era, teaching requires more knowledge of multiple concepts and complex relationships, 
enhanced interaction with students where they can explore more with the course materials. However, computer based training already has a relatively long history and has been shown to positively influence the amount of material learned, the time taken to learn it, and the enjoyment of the learning experience [15 and 16]. Figure-3 has shown the components of intelligent tutoring system.

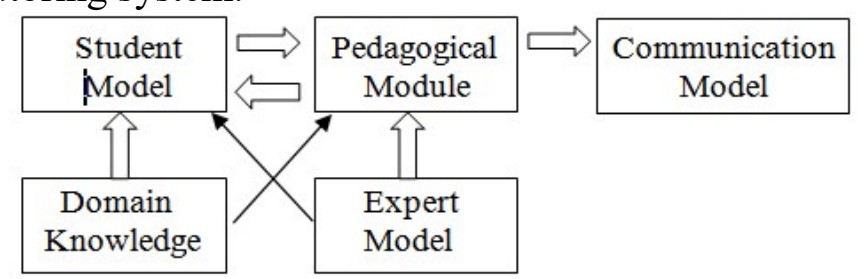

Figure 3: Components of Intelligent Tutoring System
The rapid accessibility of high-tech graphics, animation, videos, and sound capabilities and the proliferation of multimedia authoring software have made it very easy to quickly produce impressive presentations and interactive modules. Today, the technological invention makes a possibility to enhance the educational method so both educators and students become interested through the way of the learning process. From the level of primary school to university level, the application of expert system offers many advantages to support academic process.

Table 5: List of Education and Training Expert systems

\begin{tabular}{|c|c|}
\hline \multicolumn{2}{|r|}{ Education and Training Field } \\
\hline E. Systems & Descriptions \\
\hline $\begin{array}{l}\text { Computer Aided } \\
\text { Instruction(CAI) }\end{array}$ & $\begin{array}{l}\text { Primarily developed in the USA and UK. } \\
\text { It stimulates the teaching approach of an experienced teacher. } \\
\text { Teaching based on individual students according to their learning speed and abilities. } \\
\text { They are best for independent study and distance learning. } \\
\text { The CAI system is developed in three stages: Conceptual, Design and Implementation. } \\
\text { The CAI system uses multimedia to speed up the learning process in a friendly way. } \\
\text { It allows students to explore the subject by submitting queries and getting answers on the } \\
\text { spot. }\end{array}$ \\
\hline $\begin{array}{c}\text { Intelligent } \\
\text { Tutoring } \\
\text { System (ITS) }\end{array}$ & $\begin{array}{l}\text { It was primarily developed to help engineering student gain deep understanding of the } \\
\text { fundamentals to be able to follow the more advanced topics in the engineering fields. } \\
\text { The ITS is based on fuzzy logic and its gives significant flexibility in presenting the } \\
\text { information and responding to individual student needs. } \\
\text { It is highly useful for motivating students and enhancing their performance. } \\
\text { ITS will assist student in their learning by using adaptation techniques to personalize } \\
\text { with the environment, prior knowledge of the student and the student"s ability to learn. } \\
\text { Will keep a check on the student"s progress and also guides the next step in training for } \\
\text { individual students. }\end{array}$ \\
\hline $\begin{array}{l}\text { Tutoring System } \\
\text { (ITS) }\end{array}$ & $\begin{array}{l}\text { engineering student gain deep Understanding of the fundamentals to be able to follow the } \\
\text { more advanced topics in the engineering fields. } \\
\text { The ITS is based on fuzzy logic and its gives significant flexibility in presenting the } \\
\text { information and responding to individual student needs. } \\
\text { It is highly useful for motivating students and enhancing their performance. } \\
\text { ITS will assist student in their learning by using adaptation techniques to personalize with } \\
\text { the Environment, prior knowledge of the student and the student's ability to learn. } \\
\text { Will keep a check on the student's progress and also guides the next step in training for } \\
\text { individual students. }\end{array}$ \\
\hline $\begin{array}{c}\text { Intelligent } \\
\text { Pascal } \\
\text { Tutoring System } \\
\text { (IPTS) }\end{array}$ & $\begin{array}{l}\text { This expert system is used for independent teaching of Pascal to computer scholars. } \\
\text { IPTS not only teaches students in a brilliant way, but also keeps a student database for } \\
\text { checking Individual performance and learning ability. } \\
\text { It also provides the student an exercise environment to adopt a more practical loom } \\
\text { towards learning Pascal. } \\
\text { ITPS also contains an immense knowledge base for solving queries of pupils while } \\
\text { learning. }\end{array}$ \\
\hline
\end{tabular}




\section{Conclusion}

The theory of expert system is well developed \& matured and can be applied to a wide spectrum of business problems. Modern businesses, academicians, scientists, engineers, manufacturers or individual were recommended to compile resources and expertise data which significantly will benefit other people. This paper had classified the area of uncertain information of each uncertainty management deal with. Before selecting an uncertainty management, researchers should consider to which extend the expert system reason with. As highlighted in this paper, there are three areas which we have considered medicine, agriculture and education. The expert systems available in the market present a lot of opportunities for the students who desire more spotlight and time to learn the subjects. They present a friendly and interactive environment for students which motivate them to study and adopt a more practical approach towards learning. The review model is created in this paper by looking at the fundamentals of other expert systems.. This study is useful for researchers who wish to implement an uncertainty model into the expert system for a new field.

\section{References}

1. M. H. Almulla, Yahyaoui, and I. Kamal, "Trustpert: a reputation model for collaboration in MANETs using fuzzy expert system. In KCESS'11 Proceedings of the Second Kuwait Conference on e-Services and E-Systems: ACM, 2011.

2. J. Giarratano, and G. Riley, "Expert system:Principles and Programming”, 1998, Boston: PWS Publishing Company.

3. L. P. Dymova, Sevastianov, and K. Kaczmarek, "A stock trading expert system based on the rulebase evidential reasoning using Level 2 Quotes", Expert Systems with Applications, 2012.

4. N. Allahvendi, and G. Altan, "A Fuzzy expert system design to the monitor patient ${ }^{\text {ee }} \mathrm{s}$ condition during heart surgery., in CompSysTech '11 Proceedings of the 12th International Conference on Computer Systems and Technologies, 2011: ACM.

5. Definition of complex or imprecise concepts", Int J Man Mach Stud, 8, PP. 249-291, $1976 .$.
6. H. J. Zimmermann, "Fuzzy Sets, Decision Making and Expert Systems, Boston: Kluwer; 1987.

7. S. J. Liebowitz and Stephen E. Margolis, "Should technology Choice be a Concern of Antitrust Policy?", Harvard Journal of Law \& Technology, Volume No.9, PP. 284-317, 1996.

8. J. K. Kastner and S. J. Hong, "A review of expert systems". European Journal of Operational Research, Volume No. 18, PP. 285-292, 1984.

9. I. N. Saritas, N. Allahverdi and U. Sert, "A fuzzy approach for determination of prostate cancer", International Journal of Intelligent System and Applications in Engineering, Volume No. 1, PP. 01-07, 2013.

10. G. S. Tangil, J. E. Tapiador, P. P. Lopez and J. Blasco, "A text mining approach to analyzing and classifying the code structure in Android malware families, Expert Systems with Applications, Volume No. 41, PP. 1104-1117, 2014.

11. M. M. Cabrera and E. O. Edye, "Integration of Rule Based Expert System and Case Based Reasoning in an Acute Bacterial Meningitis Clinical Decision Support System", International Journal of Computer Science and Information Security, Volume No. 7, PP. 1947-5500, 2010.

12. E. H. Shortliffe, "Computer-based medical consultations: MYCIN”, Elsevier New York, Volume No.388, 1976.

13. J. Durkin, and A. Durkin, Expert systems: design and development, Prentice Hall PTR, 1998.

14. Agro-Food Processing Technology Vision 2020 Fruits \& Vegetables- Current Status \& Vision. Technology Vision 2020 Report, TIFAC, Government of India, New Delhi. 2015.

15. Satvika Khanna, Akhil Kaushik and Manoj Barnela, "Expert systems advances in Education", National conference on Computational Instrumentation CSIO Chandigarh, India, 2010.

16. S. N. Nwigbo, and O. C. Agbo, "Expert system: A Catalyst in Educational Development in Nigeria", In the Proceedings of the 1st International Technology, Education and Environment Conference, African Society for Scientific Research, 2013. 